\title{
Prospective analysis of risk factors and angiographic profile in women with coronary artery disease -A hospital based study
}

\author{
Subhasish Singh ${ }^{1}$, Rashmita Pradhan ${ }^{2}$ \\ ${ }^{1}$ Assistant Professor, Department of Cardiology, Maharaja Krishna Chandra Gajapati Medical College, Berhampur, \\ Odisha, India, ${ }^{2}$ Assistant Professor, Department of Pharmacology, S.C.B. Medical College, Cuttack, Odisha, India
}

Background: In order to facilitate diagnosis and timely intervention, it is essential to understand the presentation pattern of cardiac symptoms, and distribution of risk factors in women with Coronary Artery Disease (CAD). However, limited data is available regarding the salient features of CAD in women like distribution of risk factors and anatomical extent. Aims and Objective: The purpose of the present study was to determine the clinical and risk factor profile of women admitted with CAD and to analyze their angiographic findings in relation to the clinical presentation and risk factors in a tertiary care referral center of eastern India. Materials and Methods: In this study we prospectively analysed risk factors and angiographic patterns of 140 consecutive female patients who underwent coronary angiography for suspected CAD over a period of 2 years. Results: CAD most commonly affected females of age group $>60 y$ rs with higher incidence among postmenopausal as compared to premenopausal women. Unstable angina was the commonest presentation among patients with normal coronaries as well as obstructive CAD.A substantial percentage of women presenting with anginal pain were angiographically normal. Hypertension was the most common associated risk factor followed by diabetes, elevated total cholesterol, high LDL \& low HDL. Most common coronary angiography finding was single vessel disease. On analysis, diabetes mellitus, elevated cholesterol, elevated LDL \& triglycerides were most commonly associated with triple vessel disease. Conclusion: The incidence of CAD in females increased with age. Single vessel disease was the commonest presentation with Left Anterior Descending Artery, the most frequently involved vessel.

Key words: Angina; Coronary angiography; Coronary Artery Disease (CAD); Women
Access this article online

\section{Website:}

http://nepjol.info/index.php/AJMS DOI: 10.3126/ajms.v12i10.38403 E-ISSN: 2091-0576

P-ISSN: 2467-9100

Copyright (c) 2021 Asian Journal of Medical Sciences

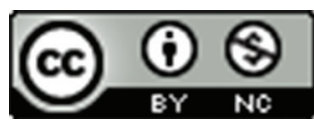

This work is licensed under a Creative Commons Attribution-NonCommercial 4.0 International License.

\section{INTRODUCTION}

In the present century, Coronary artery disease (CAD) is one of the leading cause of mortality among women in both developed and developing countries. ${ }^{1}$ In contrast to conventional belief that the disease primarily affecting men, the current data shows an increasing trend of mortality in women due to CAD than men. ${ }^{2}$ Also death due to CAD in women outnumbers that of cancers, infections, and accidents combined. ${ }^{3,4}$ The worldwide INTERHEART Study, a large cohort study of more than 52000 individuals with myocardial infarction, has revealed that women have their first presentation of coronary heart disease approximately 10 years later than men, most commonly after menopause $\mathrm{e}^{5}$ but the mortality increases as age increases as compared to men of corresponding age group. ${ }^{6}$ This increase in mortality among elderly women correlated with the steady increase in unfavourable coronary risk factors, mainly diabetes, hypertension (HTN), and metabolic syndrome. ${ }^{7,8}$ Every two of three women have at least one of the classic risk factors for heart disease i.e. age $>55$ years, family history of premature heart disease, tobacco smoking, HTN, dyslipidaemia, obesity, and diabetes mellitus. ${ }^{9}$ Previous studies suggested risk factors 
like diabetes, 10 low highdensity lipoproteincholesterol $\left(\right.$ HDLC) ${ }^{11}$ and smoking, ${ }^{12}$ elevated triglycerides ${ }^{13}$ were associated with $\mathrm{CAD}$ in women. In the Framingham study, low HDLC was shown to be a predictor of CAD, more so in women than men. ${ }^{11}$ The presence and severity of CAD in women increases linearly with age which might be due to increased prevalence of established risk factors, hormonal changes and lipid abnormalities associated with menopause and depleted estrogen levels in elderly women, but the exact association remain yet to be proven. ${ }^{14,15}$ However, limited data is available regarding study of association of risk factors and angiographic patterns of CAD in Indian women. With this background, in this present study, we aim to analyse the risk factors and angiographic profile of $\mathrm{CAD}$ in women presenting with ischemic chest pain in a tertiary care centre like S.C.B. Medical College, Cuttack.

\section{MATERIALS AND METHODS}

\section{Aims and Objectives}

The Primary objective was to study the distribution of risk factors in women with CAD.

The secondary objective was to analyze the relation between angiographic findings and risk factors in the same patient population.

\section{Study Design}

The present study was a prospective and observational study to evaluate clinical and risk factor profiles of women admitted with CAD in department of Cardiology, S.C.B. Medical College, Cuttack, for a period of 2 years. All females who were referred to the hospital for coronary angiography fulfilling inclusion \& exclusion criteria were included in the study.

\section{Inclusion criteria}

All the female patients presenting with Acute ST elevation Myocardial infarction (STEMI), unstable angina/NSTEMI, chronic stable angina in the IPD \&OPD were included in the study.

\section{Exclusion Criteria}

Female patients with serious comorbid conditions whom the risk of coronary arteriography outweighs the benefit of the procedure, patients presenting with non-cardiac chest pain ( $<1$ of typical angina characteristics) and patients not willing for revascularization were excluded from the study.

From the female patients, demographic data and detail clinical history were collected by in-person interviews or by reviewing their medical records. The data collection form included age, sex, weight, height, body mass index, laboratory results such as total cholesterol, triglyceride,
FBS, LDL, and HDL, positive history of chronic disease (diabetes, hypertension, and hyperlipidaemia), smoking, family history of ischemic heart disease (first-degree relative), past history of CCU admission, previous history of coronary angiography, prior myocardial infarction, and coronary artery bypass graft or percutaneous transluminal angioplasty. All the patients were subjected to echocardiographic examination before coronary angiography, and the details regarding the presence of regional wall abnormalities, left ventricular dysfunction (Ejection fraction $<50 \%$ ) valvular heart function and pulmonary artery hypertension were noted.

\section{DEFINITIONS}

STEMI is defined as patient having any one of following criteria like characteristic chest pain suggestive of ischemia for prolonged period (>30 min) or evolutionary changes in ECG showing ST elevation of at least $1 \mathrm{~mm}$ in two contiguous limb leads or $2 \mathrm{~mm}$ in two contiguous chest leads/precordial leads or Characteristic rise or fall of enzymes (CK-MB and troponin) suggestive of myonecrosis Unstable angina/NSTEMI is defined as angina with at least one of the following i.e. occurring at rest(or minimal exertion)usually lasting more than $20 \mathrm{~min}$. or being severe and described as frank pain \&of new onset(within 1 month) or ' Occurring with a crescendo pattern. Patients with elevated biomarkers of cardiac necrosis (CPK MB, Troponin) are diagnosed having NSTEMI.The type of angina is classified as typical or atypical. Typical angina is defined according to following criteria (1) substernal chest pain described as a feeling of heaviness, squeezing, crushing, or tightness, (2) provoked by exertion or emotional stress, and (3) relieved by rest and/or nitro-glycerine within minutes. If $1-2$ of the criteria were present, the symptoms were classified as atypical angina. If none or of the criteria was present, the pain was classified as noncardiac chest pain. Hypertension was defined as patient on treatment for elevated blood pressure or a systolic pressure $\geq 140$ $\mathrm{mm} \mathrm{Hg}$ and/or diastolic pressure $\geq 90 \mathrm{mmHg}$. Diabetes was defined as fasting blood glucose equal to or $>126$ $\mathrm{mg} / \mathrm{dl}$ or 2 -h postprandial blood glucose $>200 \mathrm{mg} /$ $\mathrm{dl}$ or $\mathrm{HbA} 1 \mathrm{c} \geq 6.5 \%$ and/or patients with a history of diabetes mellitus or who are receiving antidiabetic therapy. Smoker was defined as the one who regularly smoked an average of one or more cigarettes a day for at least 1 year. Patients who had given up smoking for $>12$ months were considered ex-smokers. The family history of premature CAD was considered positive in the presence of $\mathrm{CAD}$ in a first-degree male relative 55 years or less in age and/or a first degree female relative 65 years or less in age. Patients on lipid-lowering therapy 
or lipid levels in the following range were considered to have dyslipidaemia, i.e. total cholesterol $>240 \mathrm{mg} / \mathrm{dl}$, triglycerides $>150 \mathrm{mg} / \mathrm{dl}$, LDL-cholesterol $\geq 130 \mathrm{mg} / \mathrm{dl}$ and HDL-cholesterol $\leq 40 \mathrm{mg} / \mathrm{dl}$. Overweight/obesity was labelled in those with a body mass index (BMI) $\geq 23 \mathrm{~kg} / \mathrm{m}^{2}$. Physical activity or exercise for $<150 \mathrm{~min} /$ week was used as the criteria for defining sedentary lifestyle.

The diagnosis of Acute Coronary Syndrome (ACS) was made if the patient presented with new onset symptoms suggestive of ACS within preceding 1 week with any one of the following: i.e. Electrocardiogram (ECG) changes suggestive of myocardial ischemia/infarction, elevated biomarkers of myocardial necrosis (any one of creatine kinase-muscle/brain/ Troponin-T or Troponin-I) or history of documented CAD in the past. ACS patients were categorized into ST-segment elevation myocardial infarction (STEMI) or NSTEMI/UA. STEMI was diagnosed if ECG showed evidence of ST-segment elevation in $\geq 2$ contiguous leads. The rest of the cases were labelled as NSTEMI/UA based on the presence of elevated biomarkers of myocardial necrosis

\section{Coronary angiography}

Coronary angiography was performed in our department with Siemens Image Intensifier Based Cath Lab Equipment through the femoral or radial artery approach. A minimum of two orthogonal views were obtained for each vessel. Angiograms were analysed from cine recording and reports were compared with QCA measurements for extent of stenosis. Presence, location and extent of coronary artery disease were noted. The angiographic pattern of coronary arteries was classified according to the number of major coronary arteries involved. It was called single, double, triple vessel disease (TVD) when one, two or three major coronary arteries were with $>50 \%$ luminal stenosis, respectively. The arterial segments were seen in such views that have minimal overlapping or foreshortening of the lesions. The lesions were graded as Obstructive if $\geq 50 \%$ of the luminal diameter reduction and Nonobstructive disease $\leq 50 \%$ of the luminal diameter reduction and/or irregularities of the lumen or Normal epicardial coronaries if no stenosis and no lumen irregularities.

The study protocol was approved by Institutional Ethical Committee, S.C.B. Medical College, Cuttack. The study was conducted with the patients' understanding and consent. All work was conducted in accordance with the Declaration of Helsinki (1964).

\section{STATISTICAL ANALYSIS}

Values are expressed as mean $\pm \mathrm{SD}$. The data obtained were analysed by SPSS-windows10 software system. Continuous variables were analyzed for statistical significance using the paired t test and discrete variables using the Chi-Square test.

\section{RESULTS}

A total 140 no of female patients admitted to our hospital were included in our study. It was found that the mean age of the female patient suffering from CAD was 54.19 $\pm 9.89 \mathrm{yrs}$ and maximum were from $>60 \mathrm{yrs}$ age group with post-menopausal preponderance (Figure 1).

Sixty eight percentage female showed angiographic evidences of CAD where as $32 \%$ patients had normal coronaries on angiography (Figure 2).

Unstable angina was the commonest presentation in both group of patients having normal coronaries and CAD (Figure 3).

Left anterior descending artery (41\%) was the commonest vessel involved followed by RCA (29\%) and LCX (26\%) (Figure 4).

Left Anterior Descending (LAD) is the commonest vessel, $78(41 \%)$ involved followed by Right Coronary Artery (RCA) 56 (29\%) and Left Circumflex (LCX) 50(26\%).

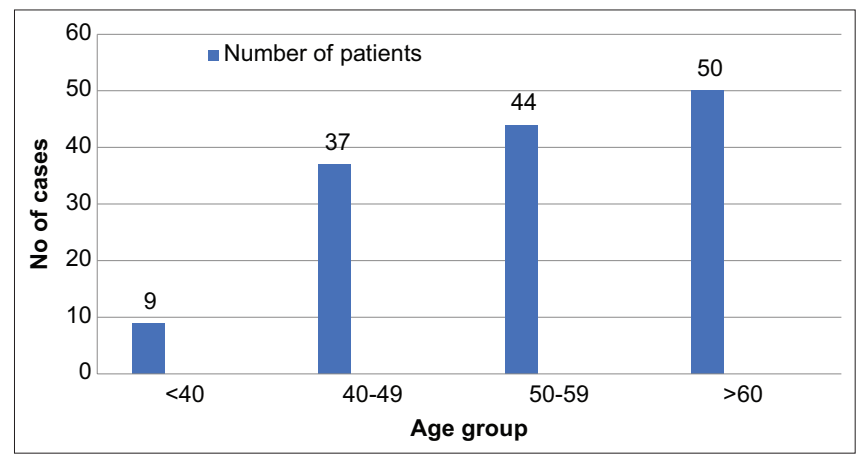

Figure 1: Age wise distribution of coronary artery disease in women

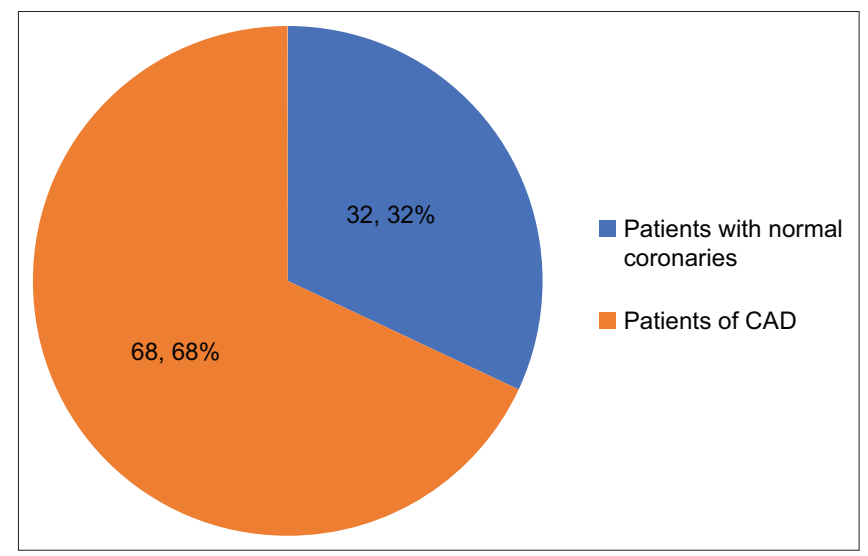

Figure 2: Patients with normal coronaries Vs patients with angiographic evidences of CAD 
Out of 49 patients who presented with chronic stable angina had normal coronaries (36\%) followed by minor lesion or $\operatorname{SVD}(22 \%$ each).In patients with unstable angina $38 \%$ had normal coronaries and SVD as the most common lesion in CAD Most patients who presented with STEMI had SVD (Figure 5).

Coronary artery disease was more common in patients with diabetes $(p=0.009)$, body mass index $\geq 25 \mathrm{~kg} / \mathrm{m}^{2}$ $(p=0.007)$, family history of premature CAD $(p=0.006)$, total cholesterol $\geq 200 \mathrm{mg} / \mathrm{dl}(\mathrm{p}=0.011), \mathrm{LDL} \geq 100 \mathrm{mg} / \mathrm{dl}$ $(\mathrm{p}=0.006)$ and HDL $\leq 40 \mathrm{mg} / \mathrm{dl}(\mathrm{p}=0.009)$. These relations were statistically significant. The others are not statistically significant (Table 1).

Triple vessel disease patients presented more with unstable angina/NSTEMI ( $\mathrm{p}=0.011)$ which is statistically significant (Table 2).

Triple vessel disease was more commonly associated with diabetes $(p=0.0231)$, total cholesterol $\geq 200 \mathrm{mg} / \mathrm{dl}$ $(\mathrm{p}=0.007) . \mathrm{LDL} \geq 100 \mathrm{mg} / \mathrm{dl}(\mathrm{p}=0.002)$ and $\mathrm{TG} \geq 150 \mathrm{mg} /$

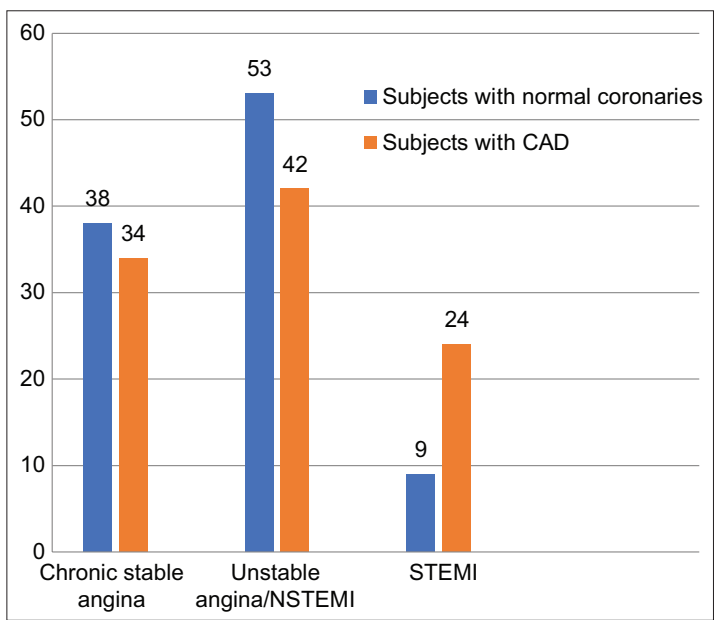

Figure 3: Type of presentation in patients with normal coronaries Vs patients with $C A D$

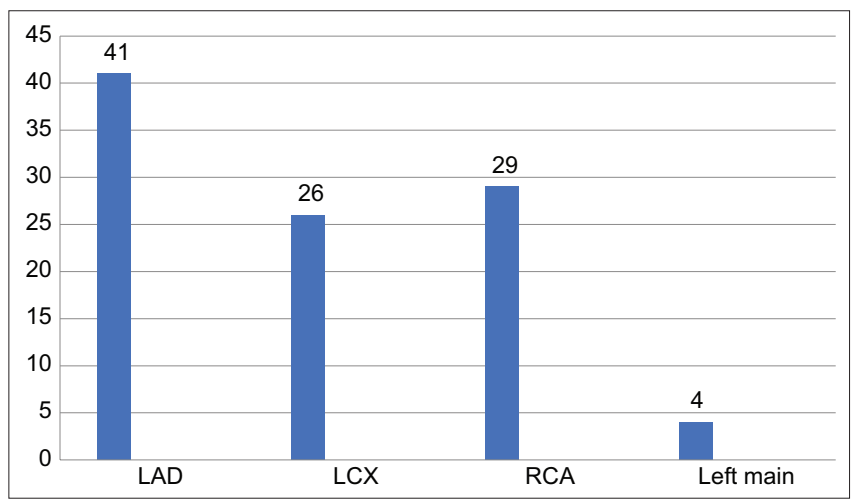

Figure 4: Angiographic profile in women with CAD. $\mathrm{dl}(\mathrm{p}=0.047)$. This relation was statistically significant (Table 3).

\section{DISCUSSION}

The present study was carried out to assess the clinical and risk factor profile of women admitted with coronary artery disease and analyse the angiographic findings in relation to these risk factors. The mean age in our study was 54.19 \pm 9.89 years but the maximum no of patients were from $>60$ years age group. This result coincided with study done by Lekha Adik Pathak 201716 where CAD was most prevalent between the age group 60-80 years and out of 3250 patients studied, 65\% were post-menopausal and $24 \%$ were post hysterectomy. In our study, incidence among postmenopausal (119 patients, (85\%) was more as compared to premenopausal (21 patients). Out of 21 premenopausal, $13(62 \%)$ had evidences of coronary artery disease on angiography. In our study, in patients with angiographically evident CAD, risk factor analysis revealed hypertension to be the commonest $(52.9 \%)$ followed by diabetes (44.3\%), tobacco chewing and passive smoking (17\%) while in a previous study raised LDL (76\%) hypertension (71\%), diabetes mellitus (63\%), reduced HDL (55\%) and obesity (54\%) among the associated risk factors. Active smoking was present only in $7 \%$ patients. The family history of Coronary artery disease (in 1st degree relatives) was found to be present in $49 \%$ of women.16 Where as in patients with normal coronaries, hypertension was the commonest risk factor $16(36 \%)$ followed by diabetes (29\%). Our study corroborates with study done by Kavita Sharma et al.,17 where the "Effectiveness-Based Guidelines for the Prevention of Coronary Artery Disease in Women-2011 Update" women were divided into 3 categories basing on their risk score i.e.: 1) high risk; 2) at risk; and 3) optimal risks.18 Women with known CAD, peripheral arterial disease, symptomatic carotid artery disease, abdominal

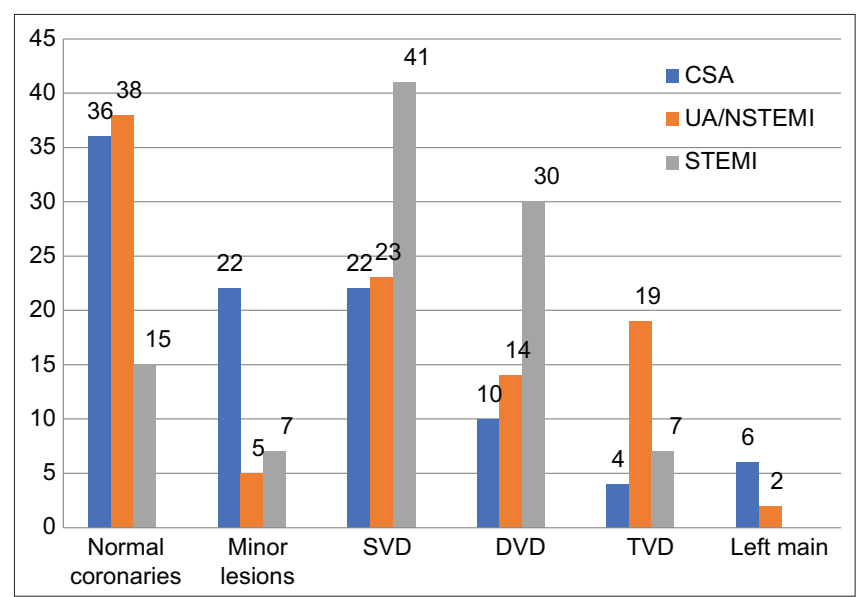

Figure 5: Relation of type of presentation with type of lesion 
aortic aneurysm, end-stage or chronic kidney disease were considered as high risk category. Whereas cigarette smoking, systolic blood pressure $\geq 120 \mathrm{~mm} \mathrm{Hg}$, diastolic blood pressure $\geq 80 \mathrm{~mm} \mathrm{Hg}$, or treated hypertension, total cholesterol $>200 \mathrm{mg} / \mathrm{dl}$, HDL cholesterol $<50$, or treated dyslipidemia, obesity, poor diet, physical inactivity, family history of premature CAD occurring in first-degree relatives in women $<65$ years of age, metabolic syndrome, evidence of advanced subclinical atherosclerosis (e.g., coronary calcification, carotid plaque, or thickened intima-media thickness) poor exercise capacity on treadmill test and/ or abnormal heart rate recovery after stopping exercise, lupus or rheumatoid arthritis or history of pre-eclampsia, gestational diabetes, or pregnancy-induced hypertension were include as at risk status. Optimal risk is defined as having all of the following factor i.e. total cholesterol $<200 \mathrm{mg} / \mathrm{dl}$ (untreated), blood pressure <120/80 mm Hg, fasting blood glucose $<100 \mathrm{mg} / \mathrm{dl}$ (untreated), body mass index $<25 \mathrm{~kg} / \mathrm{m} 2$, abstinence from smoking. Women with hypertension 19 and diabetes, 20 elevated triglycerides are greater risk factor for $\mathrm{CAD}$ in women versus men. Of the 323 women enrolled in the WISE-CVD cohort study21 who had suspected ischemic chest pain, age, hypertension, diabetes mellitus, prior MI, current hormone replacement therapy and unstable angina are all significant independent predictors of presence of significant coronary artery disease $(\mathrm{p}<0.05)$. In a similar study by Farshid Gheisari,22 older age, higher blood pressure, diabetes mellitus, previous $\mathrm{h} /$ o premature CAD, hyperlipidaemia were significantly associated with $\mathrm{CAD}$ in the female population. The higher levels of systolic and diastolic blood pressures, along with older age, were a significant risk factor in women $(\mathrm{P}<$ 0.05). Previous h/o premature CAD, diabetes mellitus, hypertension and hyperlipidemia, had a strong correlation with CAD in our female population. According to that study the most effective factor for women was previous $\mathrm{h} / \mathrm{o}$ ischemic heart disease. Olivia Manfrini9 found current smoking and diabetes disproportionately increased the risk of CAD in women. Also studies by Afsana Rahman, MST, Nurun Naher23 on "risk factor analysis of MI in females" showed hypertension, diabetes mellitus, low HDL high cholesterol, tobacco use and family h/o CAD were the most commonly associated risk factors in females with CAD. Jonathan C. Brown; Thomas E24 also found similar results i.e. hypertension, hyperlipidaemia, diabetes, obesity, family h/o premature CAD etc were the attributable risk factors for development of CAD. Out of 140 patients, 45 $(32 \%)$ had normal coronaries while $95(68 \%)$ had coronary lesions on angiography (Figure 3). The angiographic profile of women undergoing coronary angiogram (Figure 4) showed most commonly vessel to be involved was left anterior descending coronary artery (LAD) in 78 (41\%) women followed by right coronary artery (RCA) in 56
$(29 \%)$ women, left circumflex coronary artery (LCX) in $50(26 \%)$ and LMCA in $8(4 \%)$ women. This similar pattern of involvement of coronary arteries was seen in Babu Ezhumalai and Balachander Jayaraman et al.,25 where angiographic distribution of 500 patients showed involvement of LAD in $176(35.2 \%)$ women, LCX in 128 $(25.6 \%)$ women, RCA in $130(26 \%)$ women and LMCA in $17(3.4 \%)$ women. $\mathrm{LAD}$ was the most common vessel involved followed by almost equal prevalence of LCX and RCA. LMCA was the least affected vessel. Similar pattern was also observed in study done by Lu Yihua et al.26 In our study, among premenopausal women $13(62 \%)$ had CAD on coronary angiography and 8 had normal coronaries which corroborates with the previous studies done by Lu Yihua et al.,26 where $82.46 \%$ of premenopausal patients identified as ACS. One of the largest reports of angiographic findings in young patients with CAD comes from a sub study of the CASS trial. et al.27 This trial concluded that young women had a higher frequency of angiographically normal coronary arteries than young men and single vessel coronary disease was more common (24\%) as compared to triple vessel disease $(39 \%)$. Similar finding observed by Pathak where the analysis of coronary angiographic findings showed that women most commonly suffered from single vessel disease (51\%) followed by triple vessel disease (27\%), double vessel disease $(07 \%)$. Normal coronaries found to be in $15 \%$ of women undergoing coronary angiograph HDL $\leq 40 \mathrm{mg}$ / $\mathrm{dl}$ and hypertension were the most common risk factors $8(62 \%)$ followed by TG $\geq 150 \mathrm{mg} / \mathrm{dl}(46 \%)$. Diabetes was present in 5 patients $(38 \%)$.

The prevalence of cardiac risk factors and the rate of angiographically critical CAD in women under the age of 45 years for first time evaluation of chest pain were studied by De $\mathrm{S}$ et al. ${ }^{28}$ When compared with people without angiographic evidence of $\mathrm{CAD}$, women with CAD had a higher prevalence of dyslipidemia ( $72 \%$ vs $47 \%$, $\mathrm{p}=0.002)$, diabetes $(29 \%$ vs $9 \% ; \mathrm{p}<0.001)$ and smoking $(67 \%$ vs $50 \% ; \mathrm{p}=0.03)$. The association of risk factors with angiographically proven coronary artery disease was estimated in our study. The relationship between diabetes $(\mathrm{p}=0.009)$, BMI $>25 \mathrm{~kg} / \mathrm{m}^{2} \mathrm{p}=0.0070$, family history of premature CAD $(\mathrm{p}=0.006)$, total cholesterol $>200 \mathrm{mg} / \mathrm{dl}$ $(\mathrm{p}=0.011), \mathrm{LDL}>100 \mathrm{mg} / \mathrm{dl}(\mathrm{p}=0.006)$ and $\mathrm{HDL}<40 \mathrm{mg} /$ $\mathrm{dl}(\mathrm{p}=0.009)$ was found to be statistically significant. Similar findings were reported by Kunal Mahajan where the risk factors present in triple vessel disease were analyse d.Triple vessel disease, was more in those with diabetes mellitus $(\mathrm{p}=0.0231)$, total cholesterol $>200 \mathrm{mg} / \mathrm{dl}(\mathrm{p}=0.007), \mathrm{LDL}$ $>100 \mathrm{mg} / \mathrm{dl}(\mathrm{p}=0.002)$ and $\mathrm{TG}>150 \mathrm{mg} / \mathrm{dl}(\mathrm{p}=0.047)$. This relation was statistical significant. ${ }^{29}$ Out of 45 patients with normal coronaries, 53\% (24 patients) presented with unstable angina/NSTEMI, 38\% (17 patients) with chronic stable angina and 9\% (4) with STEMI. Among 95 


\begin{tabular}{|c|c|c|c|c|}
\hline \multirow[t]{2}{*}{ Risk factors } & \multirow[t]{2}{*}{ Total no } & \multicolumn{2}{|c|}{ Coronary artery disease } & \multirow[t]{2}{*}{$P$ value } \\
\hline & & Present & Absent & \\
\hline Diabetes & 45 & 39 & 6 & $0.009^{*}$ \\
\hline Without Diabetes & 95 & 56 & 39 & \\
\hline Hypertension & 71 & 55 & 16 & 0.058 \\
\hline Without Hypertension & 69 & 40 & 29 & \\
\hline Passive smoking & 20 & 16 & 4 & 0.301 \\
\hline Without Passive smoking & 120 & 79 & 41 & \\
\hline Family h/o premature CAD & 19 & 18 & 1 & $0.006^{*}$ \\
\hline NoFamily h/o premature CAD & 121 & 77 & 44 & \\
\hline Tobacco chewing & 19 & 17 & 2 & 0.304 \\
\hline Without tobacco chewing & 121 & 78 & 43 & \\
\hline $\mathrm{BM} I \geq 25 \mathrm{~kg} / \mathrm{m} 2$ & 24 & 22 & 2 & $0.007^{*}$ \\
\hline $\mathrm{BM}<25 \mathrm{~kg} / \mathrm{m} 2$ & 116 & 73 & 43 & \\
\hline Total cholesterol $\geq 200 \mathrm{mg} / \mathrm{dl}$ & 35 & 30 & 5 & $0.011^{*}$ \\
\hline Total cholesterol<200mg/dl & 105 & 65 & 40 & \\
\hline $\mathrm{LDL} \geq 100 \mathrm{mg} / \mathrm{dl}$ & 44 & 37 & 7 & $0.006^{*}$ \\
\hline $\mathrm{LDL}<100 \mathrm{mg} / \mathrm{dl}$ & 96 & 58 & 38 & \\
\hline $\mathrm{HDL} \leq 40 \mathrm{mg} / \mathrm{dl}$ & 33 & 31 & 2 & $0.009^{*}$ \\
\hline $\mathrm{HDL}>40 \mathrm{mg} / \mathrm{dl}$ & 107 & 64 & 43 & \\
\hline $\mathrm{TG} \geq 150 \mathrm{mg} / \mathrm{dl}$ & 40 & 31 & 9 & 0.161 \\
\hline $\mathrm{TG}<150 \mathrm{mg} / \mathrm{dl}$ & 100 & 64 & 36 & \\
\hline Post-menopausal & 119 & 82 & 37 & 0.613 \\
\hline Premenopausal & 21 & 13 & 8 & \\
\hline
\end{tabular}

*-statistically significant

Table 2: Correlation of patients with triple vessel disease and type of presentation

\begin{tabular}{|c|c|c|c|c|}
\hline & \multirow[t]{2}{*}{ Total no } & \multicolumn{2}{|c|}{ Triple vessel Disease } & \multirow[t]{2}{*}{$P$ value } \\
\hline & & Present & Absent & \\
\hline Chronic stable angina & 32 & 2 & 30 & \\
\hline Not presenting with Chronic stable angina & 53 & 14 & 39 & 0.079 \\
\hline UA/NSTEMI & 40 & 12 & 28 & \\
\hline Not presenting with unstable angina/NSTEMI & 55 & 4 & 51 & 0.011 \\
\hline STEMI & 23 & 2 & 21 & \\
\hline Not presenting with STEMI & 72 & 14 & 58 & 0.22 \\
\hline
\end{tabular}

patients with coronary artery disease, $42 \%(40)$ presented with unstable angina/NSTEMI, 34\% (32) with chronic stable angina and 24\% (23) with STEMI. In a similar study conducted by Pathak, ${ }^{30}$ retrospective analysis of the presenting complains found that most common indication to perform angiography was unstable angina/NSTEMI (51\%) followed by Stable Angina (25\%) and Myocardial infarction/STEMI (13\%). Similarly findings observed by Davis, ${ }^{31}$ out of 101 consecutive female patients significant coronary artery disease was unstable angina $(64.3 \%)$ followed by stable angina $(24.3 \%)$, myocardial infarction $(4.3 \%)$ and atypical chest pain in $2.8 \%$. In normal coronaries half the patients presented with atypical chest. In patients with CAD, 16(17\%) had minor lesions. Majority had significant lesions in the form of single vessel disease (37pts, 39\%), double vessel disease (22pts, 23\%), triple vessel disease (16pts, 17\%) and left main disease (4\%). So, single vessel disease was found to be most common pattern of coronary lesion. In the analysis of coronary angiogram from a large series of women enrolled in WISE study, of those with significant CAD, most had multi vessel disease. Single vessel disease was the most common pattern followed by double vessel disease. Left anterior descending artery was most commonly involved vessel followed by right coronary artery. Similar finding was observed by Pathak ${ }^{16}$ where the commonest pattern was single vessel disease (51\%) followed by triple vessel disease (27\%) and then, double vessel disease $(07 \%)$. Normal coronaries found to be in $15 \%$ of women undergoing coronary angiography. In a study by Jorge Gajardo-Navarrete et al., ${ }^{32}$ absence of coronary lesions was found in 44 and $32 \%$ of premenopausal and postmenopausal women, respectively $(\mathrm{p}<0.01)$. Premenopausal women with T2DM had a higher frequency of multi-vessel disease than those without the disease ( 25 and $4.5 \%, \mathrm{p}<0.001)$. The frequency of multi-vessel disease was higher in postmenopausal than premenopausal women (24 and 11\%, $\mathrm{p}<0.01)$. Hypertension, T2DM and renal involvement were associated with a higher frequency multiple vessel disease. 


\begin{tabular}{|c|c|c|c|c|}
\hline \multirow[t]{2}{*}{ Risk factors } & \multirow[t]{2}{*}{ Total no } & \multicolumn{2}{|c|}{ Triple vessel disease } & \multirow[t]{2}{*}{$P$ value } \\
\hline & & Present & Absent & \\
\hline Diabetes & 39 & 11 & 28 & \\
\hline Without Diabetes & 56 & 5 & 51 & 0.0231 \\
\hline Hypertension & 55 & 9 & 44 & \\
\hline without Hypertension & 40 & 7 & 35 & 1 \\
\hline Passive smoking & 16 & 1 & 15 & \\
\hline Without Passive smoking & 79 & 15 & 64 & 0.292 \\
\hline Family h/o premature CAD & 18 & 3 & 15 & \\
\hline Without Family h/o premature CAD & 77 & 13 & 64 & 1 \\
\hline Tobacco chewing & 17 & 3 & 14 & \\
\hline WithoutTobacco chewing & 78 & 13 & 65 & 1 \\
\hline $\mathrm{BM} \geq 25 \mathrm{~kg} / \mathrm{m} 2$ & 22 & 3 & 19 & \\
\hline $\mathrm{BMl}<25 \mathrm{~kg} / \mathrm{m} 2$ & 73 & 13 & 60 & 0.751 \\
\hline Total cholesterol $\geq 200 \mathrm{mg} / \mathrm{dl}$ & 30 & 10 & 20 & \\
\hline Total cholesterol $<200 \mathrm{mg} / \mathrm{dl}$ & 65 & 6 & 59 & 0.007 \\
\hline $\mathrm{LDL} \geq 100 \mathrm{mg} / \mathrm{dl}$ & 37 & 12 & 25 & \\
\hline LDL<100mg/dl & 58 & 4 & 54 & 0.002 \\
\hline HDL $\leq 40 \mathrm{mg} / \mathrm{dl}$ & 31 & 7 & 24 & \\
\hline $\mathrm{HDL}>40 \mathrm{mg} / \mathrm{dl}$ & 64 & 9 & 51 & 0.394 \\
\hline$T G \geq 150 \mathrm{mg} / \mathrm{dl}$ & 31 & 9 & 22 & \\
\hline $\mathrm{TG}<150 \mathrm{mg} / \mathrm{dl}$ & 64 & 7 & 53 & 0.047 \\
\hline
\end{tabular}

\section{CONCLUSION}

In our study, incidence of CAD is higher as the age advances and more common among postmenopausal as compared to premenopausal women. Most common presentation was unstable angina/NSTEMI. A substantial percentage of women presenting with symptoms of anginal pain had angiographically normal coronaries. So it is evident that angina as presenting symptom is less predictive of occlusive CAD in women. Among premenopausal women with CAD, hypertension and low HDL are the most common risk factors. In women with CAD, majority had single vessel disease with LAD was the most commonly involved vessel. Diabetes mellitus and BMI $\geq 25 \mathrm{~kg} / \mathrm{m} 2$, family history of premature CAD, elevated total cholesterol and LDL, low HDL are significantly associated with angiographically proven CAD in women. Women with triple vessel disease are more likely to present with unstable angina and associated with elevated total cholesterol, elevated LDL and elevated triglycerides.

\section{REFERENCES}

1. Mosca L, Mochari Greenberger H and Robb KJ. Twelve year follow up of American women's 1awareness of cardiovascular disease risk and barriers to heart health. Circ Cardiovasc Qual Outcomes. 2010; 3: 120-127.

https://doi.org/10.1161/CIRCOUTCOMES.109.915538

2. Mahajan K, Negi PC, Merwaha R, Mahajan N, Chauhan V, Asotra S, et al. Gender differences in the management of acute coronary syndrome patients: One year results from HPIAR (HP India ACS registry). Int J Cardiol. 2017; 248:1-6. https://doi.org/10.1016/j.ijcard.2017.07.028

3. Rooger VL, Go AS, Lloyd-Jones DM, Benjamin EJ, Berry JD, Borden WB, et al. Heart disease and stroke statistics - 2012 update: A report from the American Heart Association. Circulation. 2012; 125:e2- e 220.

4. Kochanek KD, Murphy SL, Xu J and Tejada-Vera B. Deaths: Final data for 2014. Natl Vital Stat Rep. 2016; 65(4):1-122.

5. Yusuf S, Hawken S, Ounpuu S, Dans T, Avezum A, Lanas F, et al. Effect of potentially modifiable risk factors associated with myocardial infarction in 52 countries (the INTERHEART study): case-control study. Lancet. 2004; 364(9438):937-952. https://doi.org/10.1016/S0140-6736(04)17018-9

6. Lori M, Manson E, Susan SE, Robert DL, Teri M and Elizabeth BC. Cardiovascular disease in women. Circulation. 1997; 96:2468-2482.

https://doi.org/10.1161/01.CIR.96.7.2468

7. Gupta RV. Trends in hypertension epidemiology in India. J Hum Hypertens. 2004; 18:73-78.

https://doi.org/10.1038/sj.jhh.1001633

8. Prabhakaran D, Chaturvedi V, Shah P, Manhapra A, Jeemon P, Shah B, et al. Differences in the prevalence of metabolic syndrome in urban and rural India: a problem of urbanization. Chronic Illn. 2007; 3:8-19. https://doi.org/10.1177/1742395307079197

9. Manfrini O, Yoon J, van der Schaar M, Kedev S, Vavlukis M, Stankovic G, et al. Sex Differences in Modifiable Risk Factors and Severity of Coronary Artery Disease. Journal of the American Heart Association. 2020; 9:e017235. https://doi.org/10.1161/JAHA.120.017235

10. Huxley R, Barzi $F$ and Woodward M. Excess risk of fatal coronary heart disease associated with diabetes in men and women: Meta analysis of 37 prospective cohort studies. BMJ. 2006; 332:73-78.

https://doi.org/10.1136/bmj.38678.389583.7C

11. Stone NJ, Robinson JG, Lichtenstein AH, Goff DC, Lloyd Jones DM, Smith SC, et al. Treatment of blood cholesterol to 
reduce atherosclerotic cardiovascular disease risk in adults: Synopsis of the 2013 American College of Cardiology/American Heart Association Cholesterol Guideline. Ann Intern Med. 2014; 160(5):339-344

https://doi.org/10.7326/M14-0126

12. Nonnemaker J, Rostron B, Hall P, MacMonegle A and Apelberg B. Mortality and economic costs from regular cigar use in the United States, 2010. Am J Public Health. 2014; 104:e86-e91.

13. Gupta R, Puri V and Narain VV. Cardiovascular risk profile in Indian women (Abstr). Indian Heart J. 1999; 51:679.

14. Bulliyya G. Risk of coronary heart disease in women after menopause. J Indian Med Assoc. 2001; 99(9):478-480.

15. Azizi $F$ and Ainy $E$. Coronary heart disease risk factors and menopause: A study in 1980 Tehranian women, the Tehran lipid and glucose study. Climacteric. 2003; 6:330-336.

https://doi.org/10.1080/cmt.6.4.330.336

16. Pathak LA, Shirodkar S, Ruparelia R and Rajebahadur J. Coronary artery disease in women. Indian Heart J. 2017; 69(4):532-538.

https://doi.org/10.1016/j.ihj.2017.05.023

17. Sharma K and Gulati M. Coronary Artery Disease in Women: $A$ 2013 Update. Global Heart.2013; 8 (2):105-112.

https://doi.org/10.1016/j.gheart.2013.02.001

18. Mosca M, Benjamin EJ, Berra K, Bezanson JL, Dolor RJ, Lloyd-Jones DM, et al. Effectiveness-based guidelines for the prevention of cardiovascular disease in women-2011 update: a guideline from the American Heart Association Circulation.2011; 123:1243-1262.

https://doi.org/10.1161/CIR.0b013e31820faaf8

19. Levy D, Larson MG, Vasan RS, Kannel WB and Ho KK. The progression from hypertension to congestive heart failure. JAMA.1996; 275(20):1557-1562.

https://doi.org/10.1001/jama.1996.03530440037034

20. Huxley R, Barzi F and Woodward M. Excess risk of fatal coronary heart disease associated with diabetes in men and women: meta-analysis of 37 prospective cohort studies. BMJ. 2006; 332(7533):73-78.

https://doi.org/10.1136/bmj.38678.389583.7C

21. Sharaf BL, Pepine CJ, Kerensky RA, Reis SE, Reichek N, Rogers WJ; WISE Study Group. Detailed angiographic analysis of women with suspected ischemic chest pain (pilot phase data from the NHLBI-sponsored Women's Ischemia Syndrome Evaluation [WISE] Study Angiographic Core Laboratory). Am J Cardiol. 2001;87(8):937-941.

https://doi.org/10.1016/S0002-9149(01)01424-2
22. Gheisari F, Emami M, Raeisi Shahraki H, Samipour $S$ and Nematollahi P. The Role of Gender in the Importance of Risk Factors for Coronary Artery Disease. Cardiol Res Pract. 2020;2020:6527820.

https://doi.org/10.1155/2020/6527820

23. Rahman A and Nurun Naher MST. A Study on Myocardial Infarction in Female-Risk Factor Analysis. International Journal of Scientific \& Engineering Research. 2016; 7(8):

24. Brown JC, Gerhardt TE and Kwon E. Risk Factors For Coronary Artery Disease. 2020. In: Stat Pearls [Internet]. Treasure Island (FL): Stat Pearls Publishing; 202132119297

25. Ezhumalai B and Jayaraman B. Angiographic prevalence and pattern of coronary artery disease in women. Indian Heart J. 2014; 66(4):422-426. https://doi.org/10.1016/j.ihj.2014.05.0091

26. Yihua L, Yun J and Dongshen Z. Coronary Artery Disease in Premenopausal and Postmenopausal Women. Int Heart J. 2017; 58(2):174-179.

https://doi.org/10.1536/ihj.16-095

27. Coronary artery surgery study (CASS): a randomized trial of coronary artery bypass surgery. Comparability of entry characteristics and survival in randomized patients and nonrandomized patients meeting randomization criteria. J Am Coll Cardiol. 1984; 3(1):114-128.

28. De $S$, Searles $G$ and Haddad $H$. The prevalence of cardiac risk factors in women 45 years of age or younger undergoing angiography for evaluation of undiagnosed chest pain. Can J Cardiol. 2002; 18(9):945-948.

29. Mahajan K, Kandoria A, Bhardwaj R, Negi PC, Asotra S and Gupta G. Clinical and coronary angiographic profile in women presenting with anginal chest pain: Results from a single-center prospective observational study. J Nat Sc Biol Med.2019; 10 (1): 60-67. https://doi.org/10.4103/jnsbm.JNSBM_172_18

30. Pathak LA, Shirodkar S, Ruparelia R and Rajebahadur J. Coronary artery disease in women. Indian Heart J. 2017; 69(4):532-538. https://doi.org/10.1016/j.ihj.2017.05.023

31. Dave TH, Wasir HS, Prabhakaran D, Dev V, Das G, Rajani M, et al. Indian heart Journal. 1991; 43 (1): 25-29.

32. Gajardo-Navarrete J, Ibieta G, Concha M, Garcés P, Robles I, Vera-Calzaretta A, et al. Coronary artery disease in pre and postmenopausal women. The influence of type2 diabetes mellitus. Rev Med Chil. 2020; 148(2):145-150. https://doi.org/10.4067/s0034-98872020000200145

\footnotetext{
Authors Contribution:

SS- Data collection, interpretation of results, literature review, Correction and Revision of manuscript; RP- Concept, statistical analysis, First draft of manuscript preparation

Work attributed to:

Department of Cardiology, SCB Medical College, Cuttack, Odisha,India

Orcid ID:

Dr. Subhasish Singh - (1) https://orcid.org/0000-0002-7530-7408

Dr. Rashmita Pradhan - (1) https://orcid.org/0000-0002-4619-0212

Source of Support: Nil, Conflict of Interest: None declared.
} 